\title{
Using Focus Group Interviews to Analyze the Behavior of Users of New Types of Tobacco Products
}

\author{
Jinyoung Kim ${ }^{1}$, Sungkyu Lee ${ }^{1,2}$ \\ 'Korean Association on Smoking or Health, Seoul; 'Institute of Health Care Management, Hangyang University, Seoul, Korea
}

Objectives: To characterize the usage patterns of new types of tobacco products (NTTPs) to develop effective strategies for the regulation of NTTPs in Korea.

Methods: We conducted focus group interviews to identify the NTTP usage patterns of research subjects. The NTTPs were limited to electronic cigarettes (e-cigarettes), waterpipe tobacco, and rolling tobacco. We categorized 30 research subjects into 4 groups. The ecigarette group was divided into adult and adolescent groups. Each group contained 7-8 subjects. An interview lasting approximately 2 hours was conducted with each group.

Results: Ninety percent of NTTP users used an NTTP in combination with conventional cigarettes. Subjects mostly bought NTTPs online, unlike how they bought cigarettes. Additionally, a great deal of information, such as how to use NTTPs and descriptions of NTTP products, was exchanged through online or offline societies. The primary reason why the subjects used NTTPs was that NTTPs offer a greater range of flavors and aromas than cigarettes. Moreover, NTTPs were felt to be less repulsive than cigarettes. NTTPs were not used as a cigarette substitute; rather, they were mostly used in places and situations where traditional cigarette smoking was not allowed.

Conclusions: Based on the results of this study, the government should conduct studies on the effects of the combined use of NTTPs and cigarettes on the human body, obtain and provide accurate data regarding NTTP use, and develop and implement polices to ban NTTP advertising, which may arouse adolescents' curiosity, and the addition of flavoring substances to tobacco products.

Key words: Tobacco, Tobacco products, Electronic cigarettes, Smoking

\section{INTRODUCTION}

Globally, the major risk factors for non-communicable diseases (NCDs), such as smoking, drinking, and unhealthy eating

Received: April 7, 2017 Accepted: September 18, 2017

Corresponding author: Sungkyu Lee, PhD

22 Gukhoe-daero 72-gil, Yeongdeungpo-gu, Seoul 07238, Korea

Tel: +82-2-2632- 5190, Fax: +82-2-2632- 5191

E-mail: wwwvince77@gmail.com

This is an Open Access article distributed under the terms of the Creative Commons Attribution Non-Commercial License (http://creativecommons.org/licenses/by$\mathrm{nc} / 4.0 /$ ) which permits unrestricted non-commercial use, distribution, and reproduction in any medium, provided the original work is properly cited. habits, are aggressively controlled under what is called the "best buys" strategy to reduce the risk of the incidence of NCDs, including cardiovascular diseases [1]. In particular, smoking is widely known as a major risk factor for a diverse range of diseases [2].

As of 2015, the adult male smoking rate in Korea was 39.3\%; this figure reflects a 3.8 percentage point decrease compared to 2014 , which was likely due to the strengthening of tobacco control policies in 2015 . This is the lowest male smoking rate ever observed since the Korea National Health and Nutrition Examination Survey (KNHANES) was first conducted [3]. Nevertheless, the adult male smoking rate in Korea is still high 
compared with other Organization for Economic Cooperation and Development member states [4]. Moreover, about 58000 people die of smoking-attributable diseases annually [5].

The international community is strengthening tobacco control policies based on the World Health Organization Framework Convention on Tobacco Control (FCTC), which became effective in 2005. Korea ratified the FCTC in May 2005 and has adopted aggressive tobacco control policies based on the convention, including implementation of a smoking ban in all restaurants, a cigarette tax increase, and the application of pictorial health warning labels to cigarette packs $[6,7]$.

Such developments were expected to encourage smokers to attempt to quit smoking and to increase the quit rate. However, new types of tobacco products (NTTPs) ambushed the market. NTTPs are advertised as being "safer" [8,9], "cheaper" [10], and "odorless" [11] compared to conventional cigarettes and are presented as a cigarette substitute, instead of as a smoking cessation aid, to smokers who may have decided to quit smoking after tobacco control policies were toughened.

In Korea, there is no operational legal definition of NTTPs. In general, any tobacco products that are not conventional cigarettes tend to be labeled as NTTPs [12]. In Korea, NTTP should not be understood as indicating a newly developed tobacco product in the literal sense; instead, NTTP refers to tobacco products newly introduced to Korea, although they may have been in use overseas for a long time.

The tobacco products defined as NTTPs in this study, as well as in Korea in general, include electronic cigarette (e-cigarettes), snus, snuff, chewing tobacco, rolling tobacco, and waterpipe tobacco, or hookah.

As regulations on cigarette smoking have been toughened by strengthened tobacco control policies, the advent of NTTPs (advertised as cigarette substitutes) may lead smokers to consume more tobacco products. NTTPs are not only expected to draw more attention from current smokers, but also from nonsmokers, as it is easier to start using NTTPs than to start smoking cigarettes.

In Korea, providing countermeasures against all tobacco products other than conventional cigarettes is an urgent matter. At the Seventh Session of the Conference of the Parties to the FCTC held in Delhi, India, in November 2016, a statement on the problems of e-cigarettes and corresponding policy directions was released [13]. The FCTC parties put more importance on the risks of e-cigarettes as a new nicotine delivery system than on their effects as a smoking cessation aid. As an e-cigarette-related policy option, the parties are recommended that those member parties where e-cigarettes are not available should ban the sales of e-cigarettes, and those where the products are already available should ban e-cigarette-related advertising and promotional activities [13]. Moreover, the controversy over heat-not-burn tobacco, which Philip Morris International developed recently, entered the spotlight. The manufacturer argues that heated tobacco is less harmful than combusted cigarettes and carries out active marketing and promotion activities, centering on Japan and Korea.

The smoking behavior of smokers is changing under the strengthened tobacco control policies, and the public interest in NTTPs is growing. In this regard, identifying smokers' perceptions of NTTPs and the behavior of actual NTTP users will play an important role in advancing tobacco control policies in the future. Therefore, in this study, we aimed to identify NTTP users' purpose for using NTTPs, their usage patterns and buying behavior, the combined use of cigarettes and NTTPs, and perceptions of NTTPs, by conducting focus group interviews (FGls) with real NTTP users. Furthermore, we suggest strategies to control NTTPs in the future, based on the results of this study.

\section{METHODS}

\section{Research Method and Design}

Despite the vast range of NTTPs available in the Korean market, due to limitations in the research period and budget, we analyzed 3 types of NTTPs in this study: e-cigarettes, waterpipe tobacco, and rolling tobacco. We analyzed the usage patterns of these products. We applied grounded theory, a qualitative research approach suggested by Strauss and Corbin [14], to this study. Grounded theory is applicable to situations in which a conceptual frame suitable for certain phenomena has not been clearly identified, meaning that there is a lack of understanding of the relationship between concepts, or for which a replication study on a certain problem has not been conducted, meaning that the proper variables related to the given problem cannot be determined [14].

We selected current NTTP users as participants in this study and conducted FGIs. FGI is a discussion method to draw out participants' perceptions or ideas on a certain topic. The goal of the activity is not to reach consensus among participants' ideas or opinions on the selected topic; rather, it is to elicit the ideas or opinions of participants on the given topic. In other words, $\mathrm{FGl}$ is a qualitative research method that can be used 
to gather information on the experiences, ideas, and beliefs of participants via interactions among the studied group [15]. In this study, the FGIs were conducted by Gallup Korea, a research firm.

\section{Participants}

FGI participants were selected according to the theoretical sampling methods suggested by Strauss and Corbin [14]. For open sampling, we classified smokers who currently smoked e-cigarettes, waterpipe tobacco, and rolling tobacco into adults and adolescents. Participants were recruited via Gallup Korea. The final research participants were all male. For e-cigarettes, which showed the highest percentage of use among the 3 NTTPs, we divided adolescent and adult users into separate groups. A total of 30 subjects participated in this study: 7 in the adolescent e-cigarette group, 8 in the adult e-cigarette group, 7 in the waterpipe tobacco group, and 8 in the rolling tobacco group.

The inclusion criteria for FGI were being a user of the given NTTP for at least 3 months on a regular basis or smoking an NTTP for 8 minutes or longer per smoking session as of the time point when the research was conducted, although there may have been some variation depending on the NTTP type.
For the e-cigarette group, we selected individuals who used devices with nicotine-containing liquid. The exclusion criteria were working in the NTTP industry (any type of NTTP) or being related to someone working in the NTTP industry, or having recently participated in a similar interview. The inclusion and exclusion criteria for the FGls are shown in Figure 1. The general characteristics of the research participants in each group are shown in Table 1.

\section{Conduct of Focus Group Interviews}

The FGls were conducted for 3 days from August 11 to August 13, 2015, in the FGI room of the headquarters of Gallup Korea, a Seoul-based research firm. Each group was interviewed for approximately 2 hours. The entire FGI process was both audiotaped and videotaped. After the FGls, scripts were obtained from Gallup Korea. The scripts and recorded materials were then compared and verified.

Before the interviews, a professional moderator were educated by the authors regarding the purpose of this research, and the FGls were conducted based on the semi-structured guidelines developed for this research via discussion with the authors. The professional moderator explained the purpose and process of this research to the participants before begin-

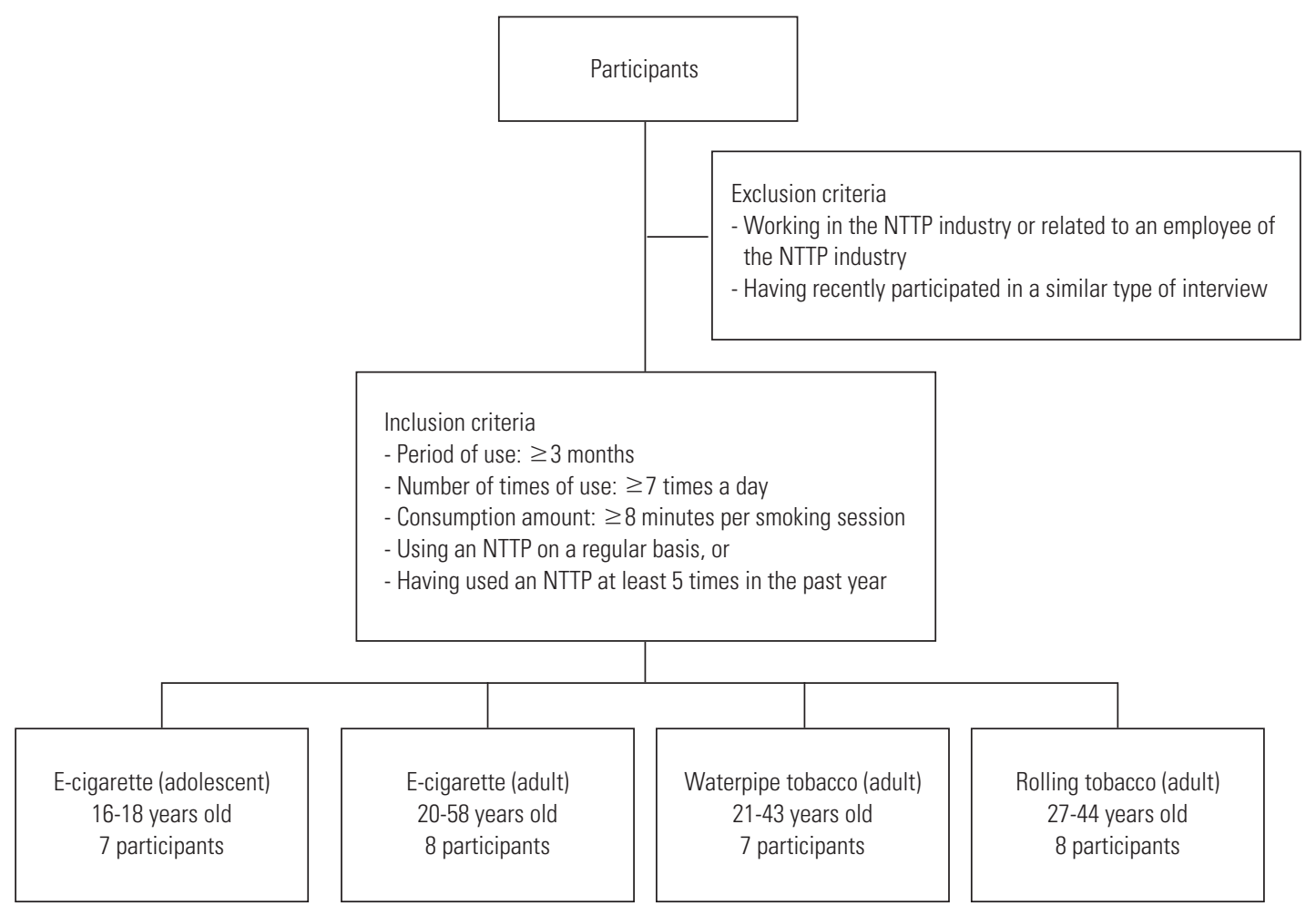

Figure 1. Inclusion criteria for focus group interviews. NTTP, new type of tobacco product; E-cigarettes, electronic cigarettes. 
Table 1. General characteristics of focus group interview participants

\begin{tabular}{|c|c|c|c|c|c|c|}
\hline Subject & Sex & Age & Occupation & $\begin{array}{l}\text { Area of } \\
\text { residence } \\
\text { (district) }\end{array}$ & $\begin{array}{l}\text { No. of times smoked in } \\
\text { the past year (waterpipe } \\
\text { tobacco, rolling tobacco)/ } \\
\text { No. of times smoked past } \\
3 \text { mo (e-cigarettes) }\end{array}$ & $\begin{array}{l}\text { Place used to smoke } \\
\text { (waterpipe tobacco) or } \\
\text { product used } \\
\text { (rolling tobacco, } \\
\text { e-cigarettes) }\end{array}$ \\
\hline $\mathrm{H} 1$ & Male & 21 & College student & Songpa & 14 times & Bar (Gangnam/Konkuk Univ) \\
\hline $\mathrm{H} 2$ & Male & 22 & College student & Seodaemun & 10 times & Bar (Hongik Univ) \\
\hline H5 & Male & 28 & Job applicant & Gangbuk & 6 times & Bar (Uijeongbu) \\
\hline H6 & Male & 40 & Self-employed & Dongjak & 5 or more times & Bar (Gangnam) \\
\hline H7 & Male & 43 & Employee (trade) & Gangseo & 80 or more times (1-2 times/wk) & Café (Gangnam) \\
\hline R1 & Male & 27 & Performance planning & Gangbuk & 10 times & Stanley \\
\hline R2 & Male & 28 & College student & Eunpyeong & 24 times & Tobacco \\
\hline R6 & Male & 40 & Welder & Seongbuk & 20 cigarettes/d & Special London \\
\hline R7 & Male & 44 & Employee & Jung & 10 cigarettes/d & Tobacco \\
\hline R8 & Male & 33 & Online shopping manager & Jongno & 3-4 times/d & Tobacco/Stanley \\
\hline EY1 & Male & 16 & High school student, first year (technical high school) & Songpa & Liberally & Haka \\
\hline EY2 & Male & 16 & High school student, third year (regular high school) & Jongno & liberally & Haka \\
\hline EY3 & Male & 18 & High school student, third year (regular high school) & Gwanak & 10 times & Haka \\
\hline EY4 & Male & 18 & High school student, second year (regular high school) & Seodaemun & 50 times & Vega \\
\hline EY5 & Male & 17 & High school student, third year (regular high school) & Yongdeungpo & Liberally & Vega \\
\hline EY6 & Male & 18 & High school student, third year (regular high school) & Gangnam & 100 times & Haka \\
\hline EY7 & Male & 18 & High school student, third year (regular high school) & Guro & 10 times & Justfog \\
\hline EA7 & Male & 58 & Employee (printing company) & Jung & 10 or more times & Justfog \\
\hline EA8 & Male & 51 & Employee (environmental agency) & Gangseo & 7 times & Haka \\
\hline
\end{tabular}

$\mathrm{H}$, waterpipe tobacco user; R, rolling tobacco user; EY, adolescent e-cigarette user; EA, adult e-cigarette user; Univ, University; e-cigarettes, electronic cigarettes

ning the FGl. Additionally, a question-and-answer session was provided to help the participants fully understand the goals of the research.

Moreover, the moderator informed the study participants about the following points and obtained their consent: the FGls both audiotaped and videotaped, and the records were stored anonymously and not be used for other purposes than research. Before beginning the $\mathrm{FGl}$, the participants filled out a simple questionnaire to provide general and smoking-related information. In the FGl, the participants were seated at a table where they faced each other. The professional modera- tor explained the rules of the interview and had everyone introduce themselves to each other before beginning the interview. The main questions were classified into the following 5 categories: 1) types of NTTPs currently used, 2) purpose of using NTTPs and duration of use, 3) how NTTPs were obtained and where NTTPs were used, 4) usage patterns and whether NTTPs were used in combination with cigarettes, and 5) perceptions of and satisfaction with NTTP.

The professional moderator moderated the FGI based on pre-prepared guidelines. The moderator adjusted the content of the questions according to the atmosphere, experience, 
Table 2. Categorization of the research content in the focus group interviews

\begin{tabular}{|c|c|c|}
\hline Content & Category 1 & Category 2 \\
\hline Pros and cons of the tobacco tax increase & \multirow{2}{*}{$\begin{array}{l}\text { Understanding and evaluation of tobacco control } \\
\text { policies }\end{array}$} & \multirow[t]{3}{*}{ Motivation for NTTP use } \\
\hline $\begin{array}{l}\text { Pros and cons of the designation of smoke-free zones and } \\
\text { smoking zones in public areas }\end{array}$ & & \\
\hline $\begin{array}{l}\text { Content of tobacco advertising as understood by participants } \\
\text { (unaware/aware) }\end{array}$ & $\begin{array}{l}\text { Awareness and evaluation of the effectiveness of } \\
\text { tobacco advertising }\end{array}$ & \\
\hline $\begin{array}{l}\text { Factors reducing criticism of NTTP use (less social blame } \\
\text { due to smell) and factors contributing to criticism of NTTP } \\
\text { use (lack of will to quit smoking) }\end{array}$ & Social awareness and personal evaluation of NTTP use & Purpose of NTTP use \\
\hline $\begin{array}{l}\text { Positive effects of NTTPs (smoking cessation aid) and } \\
\text { negative effects of NTTPs (gateway to smoking) }\end{array}$ & Evaluation of the risk of NTTP & \multirow[t]{3}{*}{$\begin{array}{l}\text { Combined use of cigarettes and } \\
\text { NTTPs }\end{array}$} \\
\hline $\begin{array}{l}\text { Place of NTTP use and frequency of NTTP use (Increased / } \\
\text { decreased cigarette consumption) }\end{array}$ & NTTP usage patterns & \\
\hline Waterpipe tobacco: flavor, aroma, social event & $\begin{array}{l}\text { Motivation for buying NTTPs and reason for continued } \\
\text { use of NTTPs }\end{array}$ & \\
\hline
\end{tabular}

NTTP, new type of tobacco product; E-cigarettes, electronic cigarettes.

and flow of each group. Notably, although there were prepared guidelines, to allow the participants to express their opinions freely, the moderator did not strictly stick to the questions. To protect the confidentiality of research participants, consent for personal information collection, use, and provision was obtained. In addition, this study was approved by the institutional review board (IRB) of the National Evidence-based Healthcare Collaborating Agency (NECA), the national research agency under the Korea Ministry of Health and Welfare (NECA IRB 15-019).

The original source material, a transcript of the interviews, was 176 pages long in A4 size. To ensure the accuracy of the source material, the authors compared and verified the recorded content with the transcripts recorded on the day of the research. Later, content analysis was conducted, in which 2 authors repeatedly read the transcripts and categorized the content. The result of the categorization is shown in Table 2.

\section{Measurement}

To identify the general characteristics of the study participants, we surveyed their sex, age, the highest level of education completed, and area of residence. To identify their smoking-related characteristics, we surveyed whether they were currently smoking, average daily cigarette consumption, total smoking period, whether they had ever tried quitting, type of NTTP tried, type of NTTP they were currently using, the satisfaction level of using the NTTP, and nicotine dependence. For nicotine dependence, we used the Fagerstrom Nicotine Tolerance Questionnaire (FTND). Based on the total of 10 possible points for 6 questions, dependence was classified as 'low' for 0-3 points; 'moderate' for 4-6 points; and 'high' for 7 or more points.

\section{RESULTS}

\section{General Characteristics and Characteristics of the Smoking Behavior of Focus Group Interviews Participants}

The total number of FGI participants was 30: 15 in the e-cigarette group ( 8 adults and 7 adolescents), 7 in the waterpipe tobacco group; and 8 in the rolling tobacco group. The mean age of each group was 36.9 years for the adult e-cigarette group, 17.4 years for the adolescent e-cigarette group, 29.1 years for the waterpipe tobacco group, and 34.3 years for the rolling tobacco group.

Ninety percent of the FGI participants (27 participants) used one or more type of NTTP in combination with conventional cigarettes; of particular note, all 7 participants in the adolescent e-cigarette group used both e-cigarettes and cigarettes. Moreover, in the adolescent e-cigarette group, 2 of the 7 showed a high nicotine dependence score ( $\geq 7$ points). Regarding their experiences attempting to quit smoking, $90.0 \%$ (27 participants) answered that they had tried quitting for 24 hours or more in the past year (Table 3). 
Table 3. Socio-demographic characteristics and smoking behaviors of focus group interview participants

\begin{tabular}{|c|c|c|c|c|}
\hline & \multicolumn{2}{|c|}{ E-cigarettes } & \multirow{2}{*}{$\begin{array}{c}\text { Waterpipe tobacco } \\
\text { Adult }(\mathrm{n}=7)^{2}\end{array}$} & \multirow{2}{*}{$\begin{array}{c}\text { Rolling tobacco } \\
\text { Adult }(\mathrm{n}=8)\end{array}$} \\
\hline & Adult $(\mathrm{n}=8)^{1}$ & Adolescent $(\mathrm{n}=7)$ & & \\
\hline \multicolumn{5}{|l|}{ General characteristics } \\
\hline Age (y) & 36.9 & 17.4 & 29.1 & 34.3 \\
\hline \multicolumn{5}{|l|}{ Level of education } \\
\hline Graduated from middle school & $1(12.5)$ & $7(100.0)$ & $0(0.0)$ & $0(0.0)$ \\
\hline Graduated from high school & $3(37.5)$ & $0(0.0)$ & $3(42.9)$ & $2(25.0)$ \\
\hline Graduated from college or higher & $4(50.0)$ & $0(0.0)$ & $4(57.1)$ & $6(75.0)$ \\
\hline \multicolumn{5}{|l|}{ Smoking behaviors } \\
\hline \multicolumn{5}{|l|}{ Smoking-related characteristics } \\
\hline Mean age of starting smoking (y) & 16.7 & 13.4 & 17.7 & 17.6 \\
\hline Mean smoking period (y) & 17.1 & 3.3 & 9.3 & 16.3 \\
\hline Combined use (cigarettes + NTTP) & $6(75.0)$ & $7(100.0)$ & $6(85.7)$ & $8(100.0)$ \\
\hline \multicolumn{5}{|l|}{ Nicotine dependence } \\
\hline Low dependence (0-3 points) & $0(0.0)$ & $3(42.8)$ & $3(50.0)$ & $3(37.5)$ \\
\hline Medium dependence (4-6 points) & $6(100.0)$ & $2(28.6)$ & $3(50.0)$ & $5(62.5)$ \\
\hline High dependence (7 or higher points) & $0(0.0)$ & $2(28.6)$ & $0(0.0)$ & $0(0.0)$ \\
\hline \multicolumn{5}{|l|}{ Tried quitting smoking? } \\
\hline No & $0(0.0)$ & $0(0.0)$ & $2(28.6)$ & $1(12.5)$ \\
\hline Yes & $8(100.0)$ & $7(100.0)$ & $5(71.4)$ & $7(87.5)$ \\
\hline
\end{tabular}

Values are presented person (\%).

NTTP, new type of tobacco product; e-cigarettes, electronic cigarettes.

${ }^{1} T$ Two participants in the adult e-cigarette group smoked e-cigarettes only, and their nicotine dependence was not evaulated.

${ }^{2}$ One participant in the waterpipe tobacco group smoked waterpipe tobacco only, and his nicotine dependence was not evaulated.

\section{How New Type of Tobacco Products (NTTPs) Were Introduced to the Participants and NTTP Buying Behavior \\ How NTTPs were introduced to the participants}

When asked how they were introduced to NTTPs, the waterpipe tobacco and rolling tobacco group answered that they mainly started NTTP use when studying or traveling abroad or through information gained from people around them or the Internet. Most of the participants in the adolescent e-cigarette group started using e-cigarettes out of curiosity and encouragement from their friends. In addition, some in the e-cigarette group and the rolling tobacco group answered that they found e-cigarettes or rolling tobacco while searching for more reasonably priced tobacco after the tobacco price increases in 2015. Regarding their buying behavior, they mostly used overseas online websites or visited offline stores to try out and buy the products.

"It has been about 5 years since I started smoking rolling tobacco. At that time, an acquaintance of mine was using rolling tobacco after returning from studying in the UK I saw that and started out of curiosity." (Ban, 40 years old, rolling tobacco)

"I smoked it for the first time in India when I was 20 years old. I saw my Indian friend smoking it and followed his example." (Park, 28 years old, waterpipe tobacco)

"I happened to learn that there was waterpipe tobacco on the Internet. I visited the store out of curiosity and liked it, so I kept going there. I and my friends smoke waterpipe tobacco by passing it around." (Yoon, 23 years old, waterpipe tobacco)

\section{How NTTPs were obtained and where NTTPs were used}

When asked about where they used NTTPs and how they purchased NTTPs, most participants in the waterpipe tobacco group answered that they smoked in a waterpipe café or bar. Two participants answered that they had bought a waterpipe tobacco device and smoked at home. For rolling tobacco, some obtained information about the tobacco from online or offline society and bought the tobacco leaves and material through group buying. Some answered that they bought tobacco leaves with a unique flavors (types not imported to Ko- 
rea) directly from overseas. For e-cigarettes, participants tried smoking in a specialized retail store where they could try an ecigarette before purchasing and bought one. Alternatively, they bought e-cigarette cartridges based on recommendations on flavors from e-cigarette users around them. All groups who participated in the FGls stated that they preferred buying an NTTP after trying one out-as there is a great range of flavors and everyone's preference varies - and they bought NTTPs in small quantities, rather than large amounts.

"Usually I buy in a retail store or from abroad. ... There are more types of tobacco leaves for rolling tobacco abroad than in Korea." (Han, 34 years old, rolling tobacco)

"When a new flavor is released, I check out the online reviews first. If I feel that it looks good, I go to an offline store to try it out." (Kim, 24 years old, e-cigarette)

"I check out reviews and exchange information in the rolling tobacco club...There are many vendors who visit the café for advertising." (Yoo, 31 years old, rolling tobacco)

\section{Dual Use of Conventional Cigarettes and New Type of Tobacco Product}

Ninety percent of the FGI participants (27 participants) reported that they used both conventional cigarettes and NTTPs. Those in the e-cigarette group were found to use ecigarettes instead of conventional cigarettes in places where cigarette smoking was not possible, such as at work or school.

Moreover, they responded that they used e-cigarettes as soon as waking up in the morning, right before going to sleep, and while waiting for buses - that is, when they were in places where it was improper to smoke cigarettes, or when they wanted to smoke but did not have enough time to smoke a whole cigarette. Furthermore, they answered they smoked ecigarettes instead of conventional cigarettes when the person next to them did not like the odor of cigarettes. However, their satisfaction level with e-cigarettes was lower than with conventional cigarettes. In addition, due to differences in nicotine absorption between e-cigarettes and conventional cigarettes, they indicated that they had to smoke more frequently and longer when smoking e-cigarettes than cigarettes.

Participants who smoked both e-cigarettes and cigarettes answered that they would rather smoke cigarettes than e-cigarettes if there were no restrictions in place. In addition, when they needed to focus on something for a long time, such as in playing a game or driving, they held e-cigarettes in their mouth to use. Therefore, they ended up smoking more than when they used cigarettes alone. Some participants in the adolescent e-cigarette group said they were trying to quit smoking by using flavor cartridges only, without nicotine, in their ecigarettes. However, they were skeptical about the effect of smoking cessation via such attempts.

"Since I started smoking e-cigarettes, I feel that I smoke conventional cigarettes less. But this does not mean that I smoke any less. In the end, because of the unique taste of conventional cigarettes, I returned [to cigarettes]." (Jang, 16 years old, e-cigarette)

"I smoke e-cigarettes only in the classroom or at home. I smoke conventional cigarettes outside...E-cigarette is a supplement to cigarettes." (Yim, 18 years old, e-cigarette)

"Because the tobacco smell gets on my body, I smoke e-cigarettes while I work. After finishing work, on my way home, I smoke conventional cigarettes." (Hwang, 40 years old, e-cigarette)

"When I wait for a bus at the bus stop, I don't smoke conventional cigarettes, because I don't know exactly when the bus will come. ... These days I smoke e-cigarettes, too. If the waiting time for the bus is long, I smoke conventional cigarettes, and if it is short, I can take 2 or 3 puffs from an e-cigarette and stop right away when the bus arrives." (Kim, 24 years old, ecigarette)

\section{Purpose for Using New Type of Tobacco Products}

The common reason why the FGI participants in all groups kept using NTTPs was 'good flavor.' They also answered that they continued using NTTPs because NTTPs offered more diverse and unique flavors than conventional cigarettes. The waterpipe tobacco group pointed out 'diverse flavors' and 'social events' as their reasons for using the product. The rolling tobacco group listed reasons including: "When compared with conventional cigarettes, rolling tobacco seems to be less harmful to the body," "it is more economical than cigarettes," it does not leave a tobacco smell on the body," and "it has good flavors."The e-cigarette group said they kept using e-cigarettes because "it is more economical than conventional cigarettes," 
"it is less restrictive," "it does not leave a smell on the body," and "it has good flavors." In short, for the waterpipe tobacco group and rolling tobacco group, 'flavor' was the most important reason for NTTP use. In the e-cigarette group, leaving no smell was the predominant answer to the same question.

"Usually, I like mint...Also, I use e-cigarettes as if it is dessert, like a strawberry cheesecake." (Lee, 18 years old, e-cigarette)

"Cigarettes feel very good when smoking them. But, afterward, the smell of rotten taste remains in my mouth and gets all over me. I feel like I become a chunk of nicotine...I use a coffee or green grape flavor when I want to refresh my mouth ..." (Kwak, 36 years old, e-cigarette)

"During the semester, there are many girls in my classes, none of whom are smokers, and the ones who do projects together don't like the tobacco smell... So I smoke only e-cigarettes when I am at school, for the most part. E-cigarettes do not leave a tobacco smell on the body so I can smoke liberally." (Kim, 20 years old, e-cigarette)

"[The reason I smoke waterpipe tobacco is] curiosity. Then, flavor." (Gong, 27 years old, waterpipe tobacco)

\section{Non-smokers' Attempts to Use New Type of Tobacco Products}

Most of the FGI participants (current smokers) used NTTPs as a cigarette substitute when they encountered spatial restrictions on smoking cigarettes, rather than as an aid to stop smoking. Moreover, they explained that there were nonsmokers who used NTTPs; NTTPs are relatively easy to try out because they are felt to be less repulsive than conventional cigarettes. In particular, for females, in one case, a non-smoker tried waterpipe tobacco and moved on to smoke cigarettes, ending up as a smoker, illustrating the gateway effect. Furthermore, in many cases, those who had quit smoking used an NTTP and then resumed conventional cigarette smoking.

"I've seen [that pattern] among women. She originally didn't smoke, but readily smoked waterpipe tobacco, and got used to nicotine, and ended up smoking cigarettes." (Yoon, 23 years old, waterpipe tobacco)

"I've seen many cases where they first start out with e-ciga- rettes and then smoke conventional cigarettes, or (non-smokers) experience e-cigarettes and keep smoking e-cigarettes." (Kim, 24 years old, e-cigarette)

\section{DISCUSSION}

We expect that more smokers will try to quit smoking under strengthened tobacco control policies, such as the tobacco tax increase in 2015, expansion of smoke-free areas, and adoption of pictorial health warnings on cigarette packaging. However, NTTPs, which may cripple toughened tobacco control policies, have started to be introduced in Korea, and many smokers are interested in these products. In this study, the authors conducted FGls with current users of e-cigarettes, rolling tobacco, and waterpipe tobacco, in order to identify their motives for using the given NTTP, their purpose for using the NTTP, and their specific experiences and usage patterns.

The results of this study revealed common NTTP usage patterns regardless of the type of NTTP. The first is the way of purchasing NTTP. Generally, people buy conventional cigarettes from tobacco retail stores, such as convenience stores $[16,17]$. In contrast, most FGI participants bought NTTPs via internet blogs or cafés, or even overseas websites if necessary.

Moreover, while tobacco companies mainly advertise cigarettes and promote brands, a variety of information on NTTPs was exchanged through online communities created by NTTP users. Under current law, tobacco should not be advertised or promoted to adolescents. However, in reality, adolescents are recklessly exposed to indirect product promotion via internet [18]. Experts and civic organizations have already pointed out this problem [18]. Nonetheless, no proper regulations have been implemented, and the online promotion of NTTPs is suspected to be very active. There is an urgent need for a strict crackdown on the online promotion and sales of conventional cigarettes, as well as NTTPs, and appropriate regulatory strategies should be developed.

Second, current users of NTTPs are using them in combination with conventional cigarettes. Promotional content for NTTPs includes statements that e-cigarettes, rolling tobacco, and waterpipe tobacco are less harmful to health than cigarettes, do not produce the unique stench of tobacco, and offer good flavors $[8,9,11]$. Possibly for these reasons, the participants of this study mostly used cigarettes in combination with NTTPs. In other words, instead of quitting cigarette smoking, they used NTTPs based on the belief that they could maintain 
their health by doing so, and in situations where they could not smoke cigarettes due to tobacco control policies. Additionally, they enjoyed the various flavors that NTTPs offer. Using cigarettes in combination with other types of tobacco may pose several problems. If NTTPs are used instead of cigarettes, it may be somewhat less harmful to health than continuing to use cigarettes alone. Nonetheless, when NTTPs are used in addition to cigarettes, without any change in cigarette consumption, the total amount of nicotine exposure increases. The combined use of cigarettes and NTTP may worsen nicotine addiction and increase the risk of nicotine-attributable vascular diseases [19]. In a prior e-cigarette-related study in 2011 that analyzed materials from the Youth Health Behavior Online Survey (YHBOS), 75\% of current e-cigarette users reported smoking e-cigarettes in combination with cigarettes [20]. The same study showed that the average daily cigarette consumption of smokers using cigarettes and e-cigarettes at the same time (combined users) was greater than that of cigarette smokers; this suggests that the total nicotine exposure of combined users is likely to be higher than that of cigarette smokers [20].

Third, NTTP users responded to the various flavors of NTTPs. Cigarette smokers who are used to the same flavor and taste become curious about the diverse flavors that NTTPs offer and use NTTPs as a way to have more fun while smoking. Such smoking behavior may serve as an obstacle in attempting to quit. Moreover, the flavors of NTTPs may mislead NTTP users to believe that NTTPs are less harmful to health than cigarettes. In other words, the strong smell and flavor and feeling of sickness from cigarettes may signal smokers that smoking is not good for their body. In contrast, the fruity aroma and aromatic fragrance of NTTPs may lead users to think that NTTPs are less harmful to their health, or even good for their health, which is a very dangerous idea. In fact, a previous study found that toxic substances such as carbon monoxide and polycyclic aromatic hydrocarbons were found in waterpipe tobacco, which allures smokers with its diverse flavors, in the same quantity as in cigarettes [21]. Moreover, compared to cigarettes, waterpipe tobacco has been reported to be associated with 2 or more times greater risks of developing lung cancer, respiratory diseases, or low birth weight in infants [22-25]. According to prior studies, the urine cotinine levels of smokers who smoke waterpipe tobacco daily are the same as those of cigarette smokers who smoke 10 cigarettes a day $[16,26,27]$. In short, if a smoker who smokes 10 cigarettes a day also smokes waterpipe tobacco daily, his or her total nicotine expo- sure will be twice as much as that of those who smoke the same number of cigarettes without NTTP use.

Another issue that warrants further discussion and examination is the gateway effect of NTTPs. It was found that in one case, a non-smoker became a cigarette smoker through exposure to NTTPs; this was reported to have occurred in an acquaintance of a FGI participant. The fact that non-smokers can become cigarette smokers through NTTPs can be considered a very strong reason supporting the need to regulate NTTPs aggressively. We need more research and discussion on this issue.

Furthermore, we need to pay attention to major NTTP-related issues within the international community. The international community is keen on the electronic nicotine delivery systems (ENDS) that tobacco companies are newly developing as a substitute for cigarettes. These products are understood to be less harmful to health than conventional cigarettes, as they do not involve a combustion process, unlike cigarettes. However, FCTC parties have raised concerns about the advent of NTTPs that still deliver an addictive substance, nicotine, albeit in different forms [13]. In Korea as well, we need to pay more attention to ENDS as well as non-cigarette products from the policy perspective and continue to monitor tobacco products that will keep evolving.

In this research, we conducted FGls with 30 NTTP users. The results of this study cannot be generalized to all NTTP users and should be interpreted with caution. Despite such limitations, this study deserves to be valued academically and from a policy perspective, because it is the first of its kind in Korea to examine the specific behaviors of actual NTTP users since the recent reinforcement of tobacco control policies. Moreover, the results of this study reflect early research into NTTPs. However, considering the addictive characteristics of tobacco, the number of users can skyrocket in a short period of time, and regulate its use may be challenging due to addiction. Therefore, the government should make efforts to implement the policy suggestions drawn from this research in the form of actual regulations. Furthermore, we used the FTND to measure nicotine dependence of research participants, both adults, and adolescents. However, as it has been pointed out that the FTND does not properly reflect the current circumstances of Korean adolescents, the results should be interpreted with care.

Based on the results of this study, we would like to make suggestions for NTTP-related regulatory policies. First, the government, academia, and civic groups should take initiative in providing accurate information regarding NTTPs to the pub- 
lic based on scientific evidence. Most information about NTTPs is recklessly distributed online; current cigarette smokers or adolescents can nurture their curiosity about NTTPs through such information. Therefore, NTTP-related online marketing and information exchange should be monitored and strictly regulated so that illegal acts will not be committed.

Second, the flavors of NTTPs-the main motivation for using NTTPs - should be strongly controlled. The US and European countries have already banned adding flavors to tobacco products. Adding flavors to NTTPs as well as cigarettes should be prohibited so that we can stop adolescents from becoming curious about tobacco products and prevent the further spread of NTTP use.

Finally, we should examine the use of tobacco products besides conventional cigarettes in the national survey system to evaluate changes in NTTP use. The KNHANES and YHBOS, the major national surveys used to investigate smoking rates, conduct surveys on cigarette smoking rates and e-cigarette smoking rates only. In contrast, the US government surveys the prevalence of the use of all tobacco products in all smoking rate studies. If we also collect prevalence data for all types of tobacco products, the results will provide very important evidence for developing NTTP-related regulation policies.

\section{ACKNOWLEDGEMENTS}

The Korea Ministry of Health and Welfare provided funding for this research (Study on changes in the use of tobacco products and regulatory strategies for new tobacco products following the reinforcement of tobacco control policies, 2015). The Ministry of Health and Welfare, the sponsor of this research, did not exert any influence on the research design, data collection, analysis, or submission of this study.

\section{CONFLICT OF INTEREST}

The authors have no conflicts of interest associated with the material presented in this paper.

\section{ORCID}

Jinyoung Kim http://orcid.org/0000-0002-7007-2312

Sungkyu Lee $h t t p: / / o r c i d . o r g / 0000-0002-6419-2086$

\section{REFERENCES}

1. World Health Organization. Global action plan for the prevention and control of NCDs 2013-2020; 2013 [cited 2017 Sep 19]. Available from: http://www.who.int/nmh/publications/ ncd-action-plan/en/.

2. World Health Organization. WHO report on the global tobacco epidemic 2013: enforcing bans on tobacco advertising, promotion and sponsorship; 2013 [cited 2017 Sep 19]. Available from: http://www.who.int/tobacco/global_report/2013/ en/index.html.

3. Korea Centers for Disease Control and Prevention. The sixth Korea National Health and Nutrition Examination Survey (KNHANES VI-2); 2014 [cited 2017 Sep 19]. Available from: https://knhanes.cdc.go.kr/knhanes/main.do (Korean).

4. Ministry of Health and Welfare. OECD health data 2015 [cited 2017 Sep 19]. Available from: file:///C:/Users/user/Downloads/OECD_Health_Data_2015\%2528\%EC\%9A\%94\%EC\%9 5\%BD\%EB\%B3\%B8\%2529_\%EC\%86\%8C\%EC\%B1\%85\%EC $\% 9 E \% 90 . p d f$.

5. Jung KJ, Yun YD, Baek SJ, Jee SH, Kim IS. Smoking-attributable mortality among Korean adults, 2012. J Korea Soc Health Inform Stat 2013;38(2):36-48 (Korean).

6. Lee KB. Government-wide comprehensive measures released for tobacco control. Money Today; 2014 Sep 11 [cited 2017 Sep 19]. Available from: http://www.mt.co.kr/view/mtview.ph p?type $=1 \&$ no $=2014091112552817143 \&$ outlink $=1$ (Korean).

7. Min MS. Bill to mandate pictorial warnings on tobacco packs passed a plenary session. Gukjenews; 2015 May 29 [cited 2017 Sep 19]. Available from: http://www.gukjenews.com/ news/articleView.html?idxno $=272485$ (Korean).

8. Yang EH, Kim IC. Indoor smoke-free policy takes a toll on a hookah café in Hongdae. NEWS1; 2015 Feb 14 [cited 2015 Apr 28]. Available from: http://news1.kr/articles/?2096281 (Korean).

9. Moon JW, Jeon BS. Is waterpipe tobacco harmless? Youth at high risk. MBN News; 2013 Dec 6 [cited 2015 Apr 28]. Available from: http://mbn.mk.co.kr/pages/news/newsView. php?category $=$ mbn00009\&news_seq_no $=1571763$ (Korean).

10. Jeong WC. Rollies are rolling in. Maeil Shinmun; 2015 Apr 3 [cited 2015 Apr 29]. Available from: http://www.imaeil.com/ sub_news/sub_news_view.php?news_id $=17874 \& y y=2015$ \#axzz3ZJwO3gK9 (Korean).

11. PAS TOBACCO. Rolling tobacco [cited 2015 Apr 29]. Available 
from: http://blog.naver.com/jhskhs8939/220306565858 (Korean).

12. Lee S, Park JY, Kim JY, Pack MJ, Park SH, Pack HN. Study on changes in the use of tobacco products and regulatory strategies for new tobacco products following the reinforcement of tobacco control policies. Seoul: National Evidence-based Healthcare Collaborating Agency; 2015, p. 4 (Korean).

13. World Health Organization. Electronic nicotine delivery systems and electronic non-nicotine delivery systems (ENDS/ ENNDS); 2016 [cited 2017 Sep 21]. Available from: http:// www.who.int/fctc/cop/cop7/FCTC_COP_7_11_EN.pdf.

14. Strauss A, Corbin J. Basics of qualitative research: grounded theory procedures and techniques. London: Sage; 1990, p. 82.

15. Krueger RA, Casey MA. Focus groups: a practical guide for applied research; 2000 [cited 2017 Sep 21]. Available from: https://cms.bsu.edu/-/media/WWW/DepartmentalContent/ Effectiveness/pdfs/LendingLibrary/Focus\%20Groups.pdf.

16. Maziak W, Jawad M, Jawad S, Ward KD, Eissenberg T, Asfar T. Interventions for waterpipe smoking cessation. Cochrane Database Syst Rev 2015;(7):CD005549.

17. Cobb C, Ward KD, Maziak W, Shihadeh AL, Eissenberg T. Waterpipe tobacco smoking: an emerging health crisis in the United States. Am J Health Behav 2010;34(3):275-285.

18. Lee $S$. Tobacco in internet blog: a call for urgent action under the FCTC. Health Soc Welf Rev 2011;31(4):405-423 (Korean).

19. National Cancer Institute. Monograph 2: smokeless tobacco or health: an international perspective [cited 2017 Sep 21]. Available from: https://cancercontrol.cancer.gov/brp/tcrb/ monographs/2/index.html.
20. Lee S, Grana RA, Glantz SA. Electronic cigarette use among Korean adolescents: a cross-sectional study of market penetration, dual use, and relationship to quit attempts and former smoking. J Adolesc Health 2014;54(6):684-690.

21. Jacob P 3rd, Abu Raddaha AH, Dempsey D, Havel C, Peng M, Yu $L$, et al. Comparison of nicotine and carcinogen exposure with water pipe and cigarette smoking. Cancer Epidemiol Biomarkers Prev 2013;22(5):765-772.

22. Koul PA, Hajni MR, Sheikh MA, Khan UH, Shah A, Khan Y, et al. Hookah smoking and lung cancer in the Kashmir valley of the Indian subcontinent. Asian Pac J Cancer Prev 2011;12(2):519524.

23. Akl EA, Gaddam S, Gunukula SK, Honeine R, Jaoude PA, Irani J. The effects of waterpipe tobacco smoking on health outcomes: a systematic review. Int J Epidemiol 2010;39(3):834857.

24. Gatrad R, Gatrad A, Sheikh A. Hookah smoking. BMJ 2007;335 (7609):20.

25. Knishkowy B, Amitai Y. Water-pipe (narghile) smoking: an emerging health risk behavior. Pediatrics 2005;116(1):e113e119.

26. Raad D, Gaddam S, Schunemann HJ, Irani J, Abou Jaoude $P$, Honeine $\mathrm{R}$, et al. Effects of water-pipe smoking on lung function: a systematic review and meta-analysis. Chest 2011;139 (4):764-774.

27. Neergaard J, Singh P, Job J, Montgomery S. Waterpipe smoking and nicotine exposure: a review of the current evidence. Nicotine Tob Res 2007;9(10):987-994. 